we must congratulate him on this thesaurus of quasi-biochemical information.

\section{HERITABLE DISORDERS OF CONNECTIVE TISSUE}

By Victor A. McKusick. St. Louis: C. V. Mosby Co., distributed in Great Britain by Henry Kimpton, London. 1960. 90s.

In the whole field of Medicine, it would be hard to pick a related series of problems more difficult than those considered in this book. The physiology of connective tissue is poorly understood; its chemistry is fragmentary; and it is not even certain that connective tissue can justifiably be treated as an entity. The inherited diseases of this enigmatic body component consist of a series of weird conditions, all rare, such as the Marfan and EhlersDanlos syndromes, osteogenesis imperfecta, pseudoxanthoma elasticum and the Hurler syndrome (gargoylism). Although these varied syndromes are readily recognisable in their fully-developed forms, patients frequently display only a few incomplete features. Since there are no specific biochemical tests at present available diagnosis has to be based on appraisal of the clinical phenomena alone, and hence is often uncertain. The medical geneticist has therefore to feel his way through a swamp of uncertainty, with only rare islets of fact on which to place his feet. The skill with which Dr. McKusick performs this difficult feat is really remarkable. Although primarily a clinician, he has marshalled what little is known of the biology and chemistry of connective tissue in a useful preliminary chapter; and in another, has provided a brilliant summary of what medical genetics is about, which should be read by any clinician who is thinking of entering this field. The remainder of the book is devoted to detailed clinical descriptions of the rare syndromes previously enumerated, together with a full account of what is known of their mode of inheritance. Anyone interested in this group of diseases will find this book quite indispensable.

TRANSPLANTATION OF TISSUES, Vol. II

Edited by Lyndon A. Peer. Pp. xiv +690 , illustrated. London: Baillière, Tindall \& Cox. 1959. I60s.

This volume is an up-to-date résumé of most of the relevant work on tissue and organ transplantation. Sections are contributed by specialists in the various fields covered and the aim of the book seems to be to provide the clinician with the salient features of this rapidly expanding field.

The difficulties in accomplishing this task are great since genetic, biochemical and especially immunological considerations, disciplines previously separated from each other and even more remote from clinical practice, are directly pertinent to tissue transplantation problems.

The editor has in the main succeeded in providing a comprehensive and readable book. The obvious defects of multiple authorship result in some repetition, a variable literary standard and occasionally disproportionate emphasis, for example 30 pages are devoted to transplantation of peritoneum, surely a very limited field, in which only autografts are of value and clinicians are already familiar with most of the applications cited.

There is an excellent chapter on the biological aspects of transplantation by Professor Medawar. This is lucid and stimulating and provides a sound scientific basis to the volume.

The references are very full and usually accurate. In some instances unhelpful historical work is mentioned apparently for the sake of completeness. In most chapters the historical backgrounds are very similar, initial early experiments on transplantation were performed with little or no distinction between autografts and homografts and interpretation of graft survival often rested on metaphysical criteria. Later work differentiated the essential technical problems of autografts from the immunological aspects of homografting. The repetition of this evolution in different chapters seems unnecessary.

Considerable space is devoted to anatomical and physiological factors that do not appear to be directly related to tissue transplantation.

A textbook on tissue transplantation is certainly due. This volume, in spite of some excessive and irrelevent content, does provide a pertinent discussion of the problems involved in experimental work and clinical applications of both autografts and homografts.

There are chapters on transplantation of the following tissues, skin, cornea, fat, nerves, teeth, blood vessels, endocrine glands, organs, peritoneum and cancer cells.

\section{THE CARE OF MINOR HAND INJURIES}

By A. E. Flatt. Pp. 266. St. Louis: The C.U. Mosby Co., distributed in Great Britain by Henry Kimpton, London. 1959. 71s. 6d.

The author has rightly criticised his own choice of title, inferring that there is no such thing as a minor injury where the hand is concerned.

The scope of this book has been restricted largely to the types of injury which can be treated in the out-patient department. As such it will be of great value to the Casualty Officer, and the Practitioner who may be obliged to treat most of his hand injuries without the resources of a large hospital at his doorstep.

The first section deals with the general principles of care and can only be criticised by someone having a rooted objection to the use of local anaesthetics.

The second section deals with the care of specific injuries and by virtue of the fact that each chapter is comprehensive, contains a lot of repetition. This 